604 Acuña-Partal y Juan Jesús Zaro, que presentan la biblioteca virtual TTLE, y resaltan el valor de las Humanidades Digitales como fuente de información sustancial para futuras investigaciones y para la labor docente. Este tipo de datos serían muy dispersos u olvidados sin el trabajo que realizan grupos de investigación con las bibliotecas electrónicas y los bases de datos. La biblioteca electrónica que se describe en el capítulo es fruto del trabajo del grupo de investigación «Traducción y Lenguajes Especializados» (HUM-800), dirigido por el catedrático de la Universidad de Málaga Juan Jesús Zaro, y se compone de las traducciones que han sido recopiladas y editadas en el desarrollo de los Proyectos de Investigación «Archivo digitalizado y edición traductológica de textos literarios y ensayísticos traducidos al español» $\mathrm{y}$ «La traducción como actividad editorial en la Andalucía del siglo xIx: Catálogo y archivo digitalizado», así como del propio Catálogo de traducciones publicadas en Andalucía en el siglo XIX. Estos proyectos de investigación cumplen con sus objetivos de rescatar y editar una selección de textos del patrimonio bibliográfico en español de inmenso valor, reuniendo no solo las traducciones de obras sino también los tratados sobre la traducción. El paso siguiente ha sido la formación del archivo digitalizado de las traducciones y sus ediciones traductológicas, y la difusión de los resultados a través de un portal de Internet, así como su explotación. La importante novedad de esta biblioteca es que las obras fueron editadas según los criterios traductológicos, algo muy valioso para el campo de los Estudios de Traducción, así como para la Historia de la Traducción en España e Hispanoamérica.

Los capítulos del presente volumen, además de presentar los resultados de unas bien fundadas e innovadoras investigaciones en el campo de la traducción e interpretación, aportan los datos y las fuentes de información que resultan realmente ventajosos para los docentes, estudiantes, profesionales e investigadores. Además, se proponen líneas de investigación novedosas que pueden tener continuidad en el futuro.

\section{La traducción de contratos de compra- venta inmobiliaria: un estudio basado en corpus aplicado a España e Irlanda}

\section{Miriam Seghiri y Lorena Arce Romeral}

Berlín, Peter Lang, 2021, 264 págs.

Míriam Pérez-Carrasco

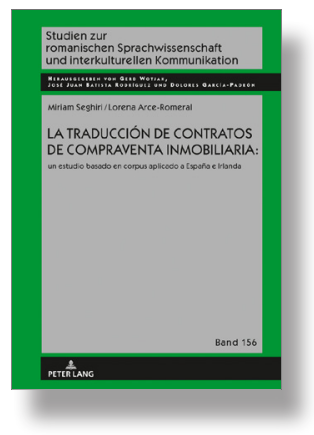

A lo largo de las 264 páginas que conforman este volumen, titulado $L a$ traducción de contratos de compraventa inmobiliaria: un estudio basado en corpus aplicado a España e Irlanda, Seghiri y Arce exponen los resultados de una investigación en la línea de la Lingüística de Corpus, aplicada en concreto a la traducción de textos del ámbito jurídico. Antes de entrar en la reseña del contenido del volumen, cabe subrayar que el trabajo que se recoge en el mismo recibió el premio George Campbell del Aula María Zambrano de Estudios Transatlánticos de la Universidad de Málaga en diciembre de 2019 por ser un contenido original y de gran utilidad para la población residente irlandesa en España, lo cual demuestra, ya de partida, la relevancia de la obra que aquí se reseña.

Seghiri y Arce plantean como hipótesis inicial que «es posible crear herramientas basadas en corpus que sean fáciles y rápidas de construir, reu- 
tilizables y de bajo coste, que ayuden al traductor en los procesos de redacción y traducción al inglés (variedad irlandesa) y al español (variedad peninsular) de contratos de compraventa de viviendas». A partir de dicha hipótesis, las autoras se plantean tres objetivos principales, en torno a los cuales versa cada uno de los capítulos de los que se compone la obra y que resumiremos a continuación.

Tras los apartados de «Prefacio» e «Introducción», encontramos el primer capítulo, La traducción de los contratos de compraventa inmobiliaria. En él, por una parte, se delimita el objeto de estudio - a saber, el contrato de compraventa de viviendas en español (variedad peninsular) y en inglés (variedad irlandesa) - ; por otra parte, se estudia el lugar que este tipo de textos ocupa dentro de la traducción especializada en general y de la traducción jurídica en particular. Destaca, asimismo, el último apartado del capítulo, centrado en la alta demanda de redacción y traducción de esta tipología textual que existe en la actualidad, lo cual viene a mostrar una vez más el interés y la relevancia de la obra de la que nos ocupamos.

En el segundo capítulo, Compilación de un corpus de compraventa inmobiliaria, las autoras se encargan de introducirnos en el campo de la Lingüística de Corpus para luego explicar pormenorizadamente los pasos seguidos para la compilación de un corpus de calidad. Destacan los criterios de diseño establecidos, así como el protocolo de compilación sistematizada que han seguido con el fin de garantizar la representatividad cualitativa y cuantitativa de la muestra. En concreto, se ha compilado un corpus integrado, a su vez, por dos subcorpus: de un lado, INMOCOR, centrado en los contratos de compraventa inmobiliaria; $y$, de otro, LEGISCOR, compuesto por textos pertenecientes a la legislación inmobiliaria. En este sentido, cabe subrayar que las autoras han incluido un apar- tado en el que exponen la legislación aplicable a 605 la compraventa inmobiliaria, tanto comunitaria (Unión Europea) como nacional (España e Irlanda), algo que puede resultar de gran valía, por ejemplo, durante las tareas de documentación del traductor que se deba enfrentar a un encargo profesional relacionado con este ámbito. Para finalizar el capítulo, Arce y Seghiri describen brevemente algunos de los programas de gestión de corpus disponibles en la actualidad y de los que se han servido para la elaboración de este trabajo. Así pues, este segundo capítulo en su conjunto resulta una preciada herramienta tanto para quienes deseen compilar sus primeros corpus e iniciarse así en el campo de la Lingüística de Corpus, como para quienes habiendo ya compilado sus propios corpus aspiren a conocer nuevas herramientas o bien seguir el protocolo de diseño propuesto por las autoras para garantizar la representatividad cualitativa y cuantitativa de la muestra, independientemente de la tipología textual con la que se trabaje.

En el tercer capítulo, titulado Uso de corpus para la traducción, extracción terminológica y creación de plantillas de redacción de contratos inmobiliarios, las autoras se proponen explotar mediante diferentes programas de gestión de corpus (en concreto, WordSmith Tools y AntConc) los subcorpus compilados. El objetivo es emplear dichos subcorpus como herramientas que puedan facilitar las siguientes tareas: la traducción directa e inversa, la extracción tanto terminológica como fraseológica, y el estudio de la macro- y microestructura de los contratos de compraventa de viviendas. Para ello, en primer lugar, se sirven del subcorpus legislativo LEGISCOR, el cual resulta de gran utilidad a la hora de realizar traducciones directas e inversas adecuándose al ordenamiento jurídico de llegada de los contratos de compraventa de vivienda en cuestión. En segundo lugar, 
606 Arce y Seghiri explotan el subcorpus INMOCOR; en concreto, extraen la terminología propia de los contratos de compraventa de viviendas en inglés y en español con el fin último de generar un glosario bilingüe y bidireccional (español-inglés/ inglés-español). Este glosario se encuentra disponible en el Anexo I, convirtiéndose así en una de las grandes aportaciones de la obra, pues supone un recurso de fácil y rápida consulta $\mathrm{y}$, por tanto, de enorme utilidad para la traducción no solo de contratos de compraventa inmobiliaria, sino también de otros géneros textuales análogos. Además, es importante destacar que la terminología especializada que contiene dicho glosario difícilmente la encontraríamos en otros recursos documentales no basados en corpus, como pueden ser glosarios o diccionarios tradicionales, por lo que el recurso presentado resulta de gran valor para la traducción de textos pertenecientes al ámbito de estudio. Por último, en este tercer capítulo las autoras se encargan de analizar la macro- y microestructura de los contratos estudiados, tanto en español como en inglés, a fin de semiautomatizar el proceso de redacción de contratos de compraventa de viviendas en España e Irlanda. Las plantillas extraídas pueden ser empleadas tanto por estudiantes y profesionales de la Traducción e Interpretación especializados en el ámbito jurídico, como por quienes se dedican al sector inmobiliario o notarial e, incluso, por aquellos particulares que desean afrontar la compraventa de una vivienda sin intermediarios.

Tras los capítulos principales de la obra, encontramos unas completas conclusiones, así como las futuras líneas de investigación que se plantean a partir de la elaboración de este estudio. Las sigue la sección Bibliografía, donde podemos encontrar todas las obras de consulta, recursos informáticos, informes, fuentes legislativas, estadísticas y artículos de prensa citados a lo largo de la obra. Además de estar ordenados alfa- béticamente, todos estos recursos están divididos por categorías, detalle que agiliza su consulta y que, sin duda, agradecerán los lectores del presente volumen a la hora de localizar una fuente bibliográfica en concreto. Cierra la obra el Anexo $I$, el cual incluye el glosario bilingüe y bidireccional (inglés-español/español-inglés) mencionado anteriormente y que resulta una de las grandes aportaciones del presente volumen.

En suma, la impecable y lógica organización por capítulos, cada uno centrado en uno de los objetivos del trabajo, así como su brillante y amena redacción, convierten a esta en una obra instructiva y muy fácil de seguir por cualquier lector, ya sea más o menos ducho en el ámbito de la Lingüística de Corpus. Asimismo, este volumen no solo viene a continuar la línea de investigación de estas autoras en Lingüística de Corpus, sino que además constituye una aportación de enorme interés en un terreno hasta ahora yermo como es el de la traducción de textos de compraventa inmobiliaria, sector que, sin embargo, y tal como se expone en el primer capítulo de la obra reseñada, cuenta con una gran demanda en el mercado actual.

Para terminar, el volumen de Arce y Seghiri demuestra una vez más la utilidad que tienen los corpus comparables a la hora de crear recursos propios para el traductor, en este caso, para aquel que se dedique a la traducción de textos jurídicos relacionados con la compraventa inmobiliaria. No obstante, cabe subrayar que la lectura de la presente obra y de todos los recursos que esta contiene puede resultar de sumo interés no solo para traductores, sino también para intérpretes, además de para juristas, lingüistas, agentes inmobiliarios, notarios e, incluso, los propios compradores y vendedores particulares de inmuebles, sobre todo en el mercado español e irlandés. En definitiva, las herramientas generadas por las autoras suponen, por un lado, un ahorro de tiempo, ya que agilizarán el proceso de 
compraventa de viviendas entre los países participantes; y, por otro lado, tendrán un impacto económico muy positivo, pues ayudarán a facilitar las transacciones entre España e Irlanda que tengan que ver con la compraventa inmobiliaria.

\section{Audiovisual Translation in Applied Lin- guistics: Educational Perspectives}

\section{LaURa InCalCaterra McLoughlin, JenNifer} LeRTOLA Y NoA TALAVÁN

Ámsterdam/Filadelfia, John Benjamins, 2020, 215 págs.

Cristina Plaza Lara

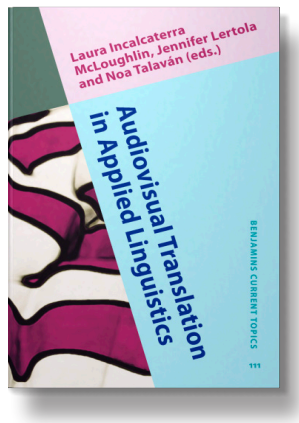

La investigación sobre el uso de la traducción audiovisual (TAV) en el aprendizaje de lenguas extranjeras se remonta a la década de los años ochenta. Desde entonces, se han sucedido los estudios sobre los beneficios de incluir las clásicas modalidades de TAV como herramientas para el aprendizaje pasivo en el aula de lenguas, hasta tal punto que prácticamente nadie con experiencia en la enseñanza o el aprendizaje de idiomas se cuestionaría su utilidad. En este sentido, los enfoques más recientes e innovadores promueven la implicación del estudiante en el proceso de creación de la TAV en sus diferentes modalidades, con el fin de favorecer el aprendizaje activo de los idiomas, al mismo tiempo que se fomentan las denominadas habilidades del siglo xxi. En esta línea gira la obra colectiva aquí reseñada, editada por Laura Incalcaterra McLoughlin, Jennifer Lertola y Noa Talaván. Como parte de la serie Benjamins $\mathrm{Cu}$ rrent Topics, de la prestigiosa editorial John Benjamins, el volumen recopila un total de ocho con- tribuciones que ponen a disposición del lector un conjunto de estudios de caso puestos en práctica en diferentes contextos. Todos ellos son replicables en otras lenguas y niveles de aprendizaje y es especialmente reseñable que los métodos de aplicación de la TAV en el aula no se limitan a su uso pasivo como refuerzo de los diferentes componentes de las competencias lingüísticas.

Ragni, autora del primer capítulo de este volumen, pone el foco de atención en el subtitulado didáctico como herramienta para hacer un uso activo de la lengua en el aula. En esta contribución se defiende la integración del enfoque basado en tareas y la instrucción basada en la forma como referentes teóricos por encima de métodos comunicativos predominantes últimamente en la enseñanza de lenguas extranjeras. Tras explicar cómo hacer uso del subtitulado didáctico desde el enfoque por tareas, la autora hace hincapié en la necesidad de prestar atención a la forma lingüística durante las tareas de subtitulado, al mismo tiempo que tiene en cuenta el proceso de aprendizaje y constructos cognitivos como la atención o la reactivación.

De la mano de Herrero y Escobar, el lector encontrará el primer capítulo de este volumen sobre audiodescripción, una de las modalidades que menos atención ha recibido hasta el momento. A partir del aprendizaje por proyectos, las autoras de esta contribución realizan una propuesta pedagógica para el aprendizaje del español como lengua extranjera basada en la realización de audiodescripciones. Ofrecen un enfoque holístico capaz de integrar las competencias lingüísticas, culturales e interculturales con la alfabetización cinematográfica. Presentan dos estudios de caso realizados en universidades británicas cuyos resultados ponen de manifiesto una mejora significativa en la alfabetización cinematográfica y en la conciencia de accesibilidad por parte de los alumnos. Si bien no ofrecen información exclusiva sobre la mejora de las competencias lingüísti- 